\title{
Modified Early Warning System (MEWS), Indicator of Changes in Patient's Condition in The General Wards: A Systematic Review
}

\author{
Zaenal Abidin \\ Master of Nursing Student, Faculty of Nursing Universitas \\ Airlangga, Surabaya, Indonesia \\ zaenalabidin19860829@gmail.com
}

\section{Alwan Revai}

Master of Nursing Student, Faculty of Nursing Universitas Airlangga, Surabaya, Indonesia

\author{
Nissa Aruming Sila \\ Master of Nursing Student, Faculty of Nursing Universitas \\ Airlangga, Surabaya, Indonesia
}

Gusti Pandi Liputo

Master of Nursing Student, Faculty of Nursing Universitas Airlangga, Surabaya, Indonesia

\begin{abstract}
Introduction: Changes in patient condition into critical condition characterized by hemodynamic changes in several indicators. Early recognition to such changes becomes nurse's responsibility, it requires a special clue or instrument to assess the changes in patient's condition. Modified Early Warning System (MEWS) is one method to assess changes in the patient's condition through some hemodynamic indicators including temperature, blood pressure, pulse, respiratory rate, and level of consciousness. Through this systematic review, researchers will assess the effectiveness of the Modified Early Warning System (MEWS) as a means of detecting changes in the patient's condition. Methods: Search of journal articles was used PECOT framework article in database; Ebscho, Science Direct, Elsevier, Sage Journals, Scopus, ProQuest, and Pub Med with limitations of publication time is in the last 10 years (2007-2017). There was 15 International journals and researchers conducted review to all of those journals. Results: Overall, those journal mentioned that the Modified Early Warning System (MEWS) was able to be applied in early detection of changes in patient's condition. Conclusion: These systematic review strongly recommend the use of the Modified Early Warning System (MEWS) as a tool to detect changes in the patient's condition.
\end{abstract}

Keywords-Modified Early Warning System, early recognition, patient deteriorating

\section{INTRODUCTION}

Changes in health services paradigm into patient-centered health services requires health workers to provide services based on patient safety, where all the processes that occur in hospital as health care providers always prioritizes the interests of patients. Treatment of patients in emergency conditions become an important focus in providing health care, assessment of the success rate in the emergency medical service system and the ability of health workers in it also become a benchmark for the quality of health services[1].
Early identification of changes in patient's condition such as cardiac arrest, shock, hypoxia, etc through hemodynamic indicator is the key to success in the process of continued treatment. Modified Early Warning System (MEWS) is one method to assess changes in the patient's condition through some hemodynamic indicators including temperature, blood pressure, pulse, respiratory rate, and level of consciousness. MEWS is a tool which is based on the physiologycal parameters and this observation should be noted on the initial assessment of patients who are unhealthy or as part of routine monitoring. Physiological parameters that govern the patient's medical condition is heart rate (pulse), blood pressure, level of consciousness and temperature[2].

The purpose of Modified Early Warning System (MEWS) is time management and treatment of patients when there is changes in their condition. Implementation of Modified Early Warning System (MEWS) is an early warning to provide emergency care of changes in patient's condition. There has not been much data which related to the implementation of Modified Early Warning System (MEWS) in Indonesia, systems already applied widely only in some developed countries.

$84 \%$ patients from related data about a decrease in patient's condition had signs of changes in conditions 8 hours before emergency condition happens and $70 \%$ had changes in respiratory function and consciousness[3]. Early detection and early treatment at the change in conditions will improve patient's life expectancy and improvements in their condition.

Through this systematic review, researchers wanted to determine the effectiveness of the implementation of the Modified Early Warning System (MEWS) as a method of detecting changes in the patient's condition so that patient can be treated properly. 


\section{METHODS}

Search of journal articles was used PECOT framework (Population: Patient in general wards, Exposure: Modified Early Warning System, Control: - , Outcome: Early detection, patient deteriorating, Time: 2007-2017). Based on the determination of keywords which is appropriate with its topic using PECOT framework and equipped with Boolean Logic method in the database; Ebscho, Science Direct, Elsevier, Sage Journals, Scopus, ProQuest, Pub Med with limitations of publication time is in the last 10 years (2007-2017), found 43 journals. 15 of those 43 journals will be more reviewed by researchers.

\section{RESULTS}

\section{A. Study Design}

This systematic review was reviewed 15 journals which have been selected. The whole journals were international journals. The study designs used include: 6 journal using retrospective study, 5 journals using prospective studies, 1 journal using exploration study, 1 journal using RCT, 1 journal using quasy experiment, and 1 journal using observational study.

\section{B. Characteristic of Participants}

It is known from 15 journals which have been reviewed, the number of sample varied between 204-3054 respondents and everything was done in adult patients at the general wards. Measuring instruments used in all research is an instrument modified early warning score. An instrument used in all research was modified early warning score.

\section{Sensitivity and Specivity}

Louise S. Van Galen et al 2016 in his prospective study mentioned that the adherence of MEWS procedure in assessing patient's condition at the hospital was good $(89 \%)$. Early detection system of three or more was a strong predictor of clinical end points such as death in the hospital, 30-day readmissions, and length of stay in hospital. In addition, the negative predictive value of MEWS <3 in population of general hospital was $98.1 \%$ which showed the effectiveness of these score as a screening tool. Therefore, it is important to constantly evaluate the effectiveness of MEWS between clinical staff.

Research by [4] mentioned that 204 patients were involved in these measurement. Within 48 hours before the incident, total of 2688 measurements of one or more vital signs were taken. Overall, $81 \%$ of patients get MEWS score 3 or more at least once during 48 hours before their condition became worse.

Research by[5] explained that 3504 patients were involved in this study. 76 patients $(2.5 \%)$ experienced adverse events within 24 hours after they came to the hospital. Pre-hospital paramedics stationed in 224 cases (7.3\%). MEWS additions to clinical assessment increased sensitivity, especially for a pathological condition with more additional clinical resources. Secondary benefit was given by PTTS, it was great enough and spend very low cost.
Research by[6] explained the MEWS ranges from 0 to 9, with higher scores representing hemodynamic instability. The average score was 2 [IQR 1-3], with an average length of stay in hospital was 9 days [IQR 4-24]. None of the patients in the cohort treated in the ICU during the study period. MEWS was higher in medical patients than surgical patients (mean 2.9 vs. $1.9, \mathrm{p}=0.001)$. There was a significant burden of critical illness in Mulago Hospital, Uganda. The implementation of MEWS could provide useful triage tool to identify patients who are at greatest risk of death.

Research by[7] explained the patients in intervention group was the same. The introduction of MEWS was not associated statistically with the changes in response to clinical deterioration (50 of 57 did not receive assistance to 55 of 57 , the odds ratio (OR): $0.26,95 \%$ confidence interval (CI): 0.05 to 1,31$)$, despite there was an increase in nurses knowledge on the wards which is given intervention by researchers. More patients in intervention group than control group have respiratory rate record (27 of 57 versus 2 of 57, OR: 24,75, 95\% CI: 5.5 to 111.3 ) and records of all 7 parameters (5 of 57 versus 0 of 57 patients, estimated risk: $1.10,95 \%$ CI: 1.01 to 1.2).

Research by [4] explained the MEWS calculation of vital signs occurred in $70 \%(2513 / 3585)$ on the intervention group compared to $2 \%(65 / 3013)$ in control group. Adherence of intervention group was $68 \%(819 / 1205)$, while adherence in control group was $4 \%$ (47/1232) from measurement. There were 90 calls to the general practitioner in intervention group and 9 calls in control group. In addition to the intervention group, there were two RRT calls.

In the journal entitled Comparative Modified Early Warning Score and Value of Systolic Blood Pressure[8], Glasgow Coma Scale in the assessment of critically ill patients at the Emergency Department [8] mentioned that when MEWS compared to GAP score in prediction of 4 weeks of death, there was no significant difference was found between them ( $\mathrm{P}>0.05)$. Strength of mortality estimates found significant for both scoring systems $(\mathrm{P}<0.001)$.

Research by [9] explained that in the period of second audit compared to the first audit, the number of heart attacks decreased significantly $(0.2 \%$ versus $0.4 \%$; p < 0.0001$)$, the proportion of patients entered intensive care after CPR in the hospital decreased significantly $(2 \%$ vs. $3 \% ; \mathrm{p}=0.004)$ as well as the mortality rate of patients $(42 \%$ versus $52 \%$; $=$ $0.05)$.

Research by[10] explained that after received training, the staff were more likely to calculate a score EWS correctly $(68.02 \%$ versus $55.12 \%$; risk ratio $[R R]=1.24,95 \%$ confidence interval $[\mathrm{CI}]=1.07-1.44)$, and observations may performed at the appropriate frequency $(78.57 \%$ versus $68.09 \% ; \mathrm{RR}=1.20,95 \% \mathrm{CI}=1.09$ to 1.32 ). 


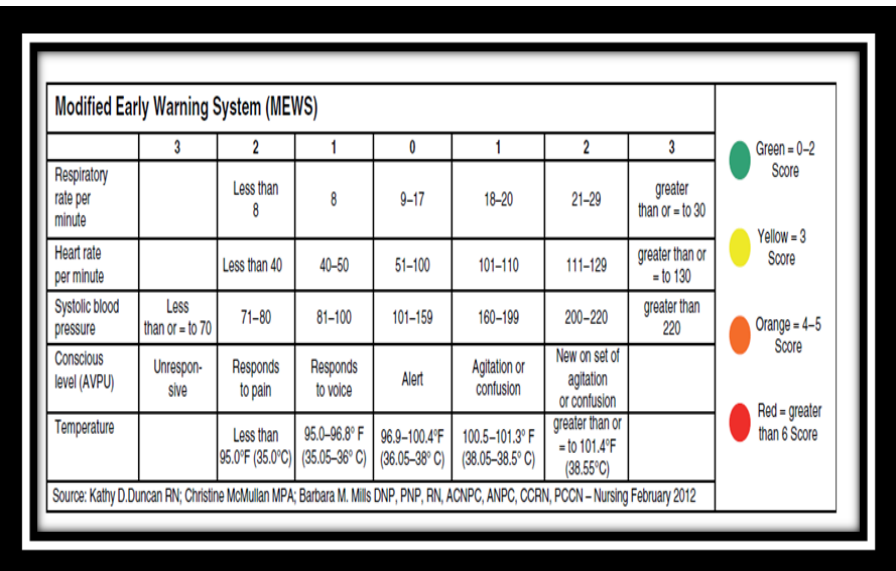

Fig. 1. Modified Early Warning System (MEWS)

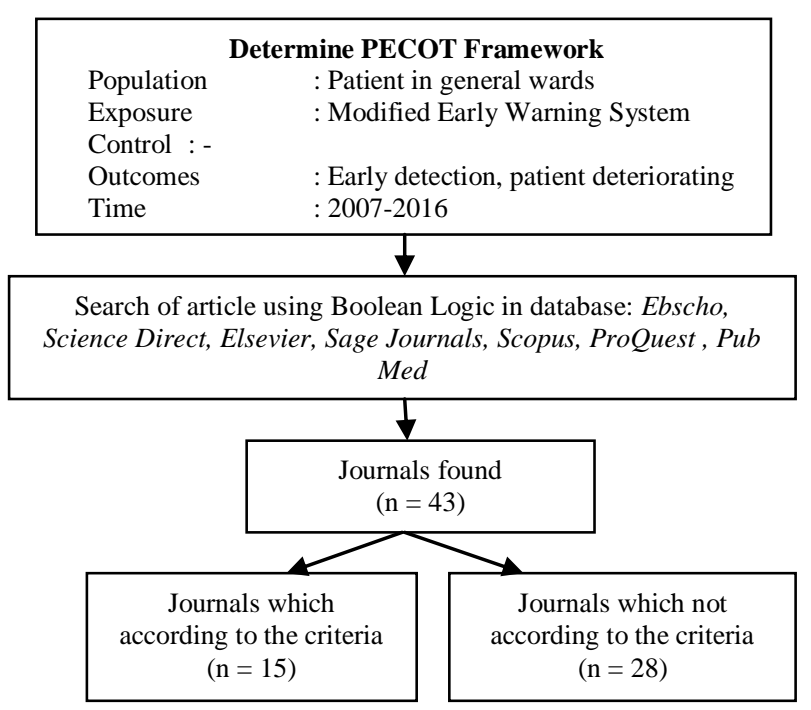

Fig. 2. Search Algorithm of Journal

Research by [3] explained that since the implementation of MEWS, the number of RRT has increased from 0.24 per 100PD in 2011, 0.38 per 100PD in 2013, and 0.48 per 100PD in 2014. The percentage of RRTs growing was for Code Blue, an indicator of poor outcome from the RRT has declined. While the number of Code Blue in non-ICU floor has declined from 0.05 per 100PD in 2011, 0.02 per 100PD in 2013 and 2014. These clinical results increased associated with the decrease of mortality rate in wards from $2.3 \%$ in 2011 to $1.5 \%$ in 2013 and $1.2 \%$ in 2014.

Research by[11] explained that the period of 30 months, 234 patients suffering cardiac arrest during the emergency, and 99 patients with Periarrest MEWS included in the final analysis. Periarrest MEWS lower in survival-to-discharge group (4.41 2.28 versus 5.82 2.84, p Z 0.053). The increase of Periarrest MEWS reduces the chance of survival-to-discharge of 0.77 times (95\% CI: 0.60e $0.97, \mathrm{p} \mathrm{Z} 0.028$ ).
Research by [12] explained that after the implementation of MEWS, the observation chart showed an increase (210\%) in the overall documentation which related to the important indicators during the first 24 hours post-ICU discharge $(95 \%$ CI 148, 288\%, p <0.001). The frequency of vital signs measurement increased since monitoring was conducted using MEWS. Specifically, T increased by $26 \%$ (95\% CI 8, 46\%, p value $=0.003)$. Increased frequency of those measurements followed by an increase in the early recognition of patient in ICU $(44 \%, 95 \%$ CI $2,102 \%$, p value $=0.035)$.

Research by [13] explained that the agreement between RNS who using MEWS tools to help nurses and then collaborate with MICN, helping them to make a better decisions for their patients.

Research by [14] showed that 57 (17\%) of 334 patients in wards which selected according to the algorithm, has value of MEWS 4 or more. There was an increase in activation of the alarm system from $8 \%$ to $22 \%$ in patients who experienced criticalness condition.

Research by [15] mentioned that the number of patients who experienced IHCA with the score of each were: score 6,1 of 556 patients $(0.18 \%)$; score 7,4 of $289(1.40 \%)$; score 8,2 of $114(1.75 \%)$; and score 9 or more, 2 of $56(3.57 \%)$. Rate of IHCAs per 1000 patient admission decreased significantly from $5.21(79 / 15.170)$ to $2.05(43 / 17.961)$ ( p <0.01).

Research by [4] explained that the calculation of MEWS from vital signs occurred in $70 \%(2513 / 3585)$ in intervention group versus $2 \%(65 / 3013)$ in control group.

\section{DISCUSSION}

The National Confidential Inquiry into patient outcome and death [16] identified the main cause of treatment which is not according to the standard of the hospital was delayed recognition (detection) and improper actions from the hospital. This report found that in some of opportunity, these factors were aggravated by poor communication between acute care and critical care medical teams [17]. The recognition, response, and treatment of deteriorating patients were an important element to improve patient outcomes and reduce an unexpected death in the general wards of hospital. The recognition of clinical changes along with appropriate early intervention can prevent adverse outcomes including heart attacks and death[11].

Through the Modified Early Warning System (MEWS) method, it is expected to facilitate nurse in the general wards to detect a decrease in patient's condition, so treatment can be done more optimally. With the identification of the changes in patient's condition the nurse had to take a decision, thus the potential for cardiac arrest or death can be minimized. Modified Early Warning System (MEWS) method was very easy to apply, familiar, required less time and effort in its implementation so that the nurses can make decisions and treat the patient quickly. 


\section{CONCLUSION}

Modified Early Warning System (MEWS) is a method which can detect early changes in patient's condition, through this the worsening of patient's condition can be known and treated properly. Early detection and prompt treatment can improve the prognosis and life expectancy for patients themselves, it can increase patient safety and improve the quality of health services.

Modified Early Warning System (MEWS) is a method which very applicable and easy to apply by nurse in general wards to assess changes in patient's condition and this system can be applied in health services in Indonesia.

\section{References}

[1] Komisi Akreditasi Rumah Sakit (KARS), "Standart Akreditasi Rumah Sakit," 2012.

[2] NHS, "Acutely ill patients in hospital Recognition of and response to acute illness in adults in hospital," 2007.

[3] C. Mathukia, W. Fan, K. Vadyak, C. Biege, and M. Krishnamurthy, "Modified Early Warning System improves patient safety and clinical outcomes in an academic community hospital," J Community Hosp Intern Med Perspect., vol. 5, no. 2, 2015

[4] J. Ludikhuize, S. Smorenburg, S. de Rooij, and E. de Jonge, "Identification of deteriorating patients on general wards; measurement of vital parameters and potential effectiveness of the Modified Early Warning Score," J Crit Care, vol. 27, no. 4, 2012.

[5] J. Fullerton, C. Price, N. Silvey, S. Brace, and G. Perkins, "Is the Modified Early Warning Score (MEWS) superior to clinician judgement in detecting critical illness in the pre-hospital environment?," Resuscitation, vol. 83, no. 5, pp. 557-62, 2012.

[6] R. Kruisselbrink, A. Kwizera, M. Crowther, A. Fox-Robichaud, T O'Shea, J. Nakibuuka, I. Ssinabulya, J. Nalyazi, A. Bonner, T. Devji, J. Wong, and D. Cook, "Modified Early Warning Score (MEWS) Identifies Critical Illness among Ward Patients in a Resource Restricted Setting in Kampala, Uganda: A Prospective Observational Study," Ploss one, vol. 11, no. 3, 2016.
[7] U. Kyriacos, J. Jelsma, M. James, and S. Jordan, "Early warning scoring systems versus standard observations charts for wards in South Africa: a cluster randomized controlled trial," trial, vol. 16, no. 103, 2015.

[8] Ö. Köksal, G. Torun, E. Ahun, D. Sığırlı, S. Güney, and M. Aydın, "The comparison of modified early warning score and Glasgow coma scaleage-systolic blood pressure scores in the assessment of nontraumatic critical patients in Emergency Department," Niger. J. Clin. Pract., vol. 19 , no. 6, pp. 761-765, 2016.

[9] J. R. Moon, M. M. Glymour, S. V Subramanian, M. Avendaño, and I Kawachi, "Transition to retirement and risk of cardiovascular disease: Prospective analysis of the US Health and Retirement Study," Soc Sci Med., vol. 75, no. 3, p. 526-530., 2012.

[10] A. Merriel, N. van der, S. Merriel, J. Bennett, F. Donald, T. Draycott, and D. Siassakos, "Identifying Deteriorating Patients Through Multidisciplinary Team Training,” Am J Med Qual., vol. 31, no. 6, pp. 589-595, 2016.

[11] A.-Y. Wang, C.-C. Fang, S.-C. Chen, S.-H. Tsai, and W.-F. Kao, "Periarrest Modified Early Warning Score (MEWS) Predicts the Outcome of In-Hospital Cardiac Arrest," J Formos Med Assoc, vol. 115 , no. 2, pp. 76-82, 2015.

[12] N. E. Hammond, A. J. Spooner, A. G. Barnett, A. Corley, P. Brown, and J. F. Fraser, "The Effect of Implementing a Modified Early Warning Scoring (MEWS) System on the Adequacy of Vital Sign Documentation," Pubmed, vol. 26, no. 1, pp. 18-22, 2012.

[13] S. K. Stafseth, S. Grønbeck, T. Lien, I. Randen, and A. Lerdal', "The experiences of nurses implementing the Modified Early Warning Score and a 24-hour on-call Mobile Intensive Care Nurse: An exploratory study," intensive Crit. care, vol. 34, pp. 33-41, 2016

[14] J. Gardner-Thorpe, N. Love, J. Wrightson, S. Walsh, and N. Keeling, "The value of Modified Early Warning Score (MEWS) in surgical inpatients: a prospective observational study," Ann R Coll Sur Engl, vol 88 , no. 6, pp. 571-5, 2006

[15] I. Nishijima, S. Oyadomari, S. Maedomari, R. Toma, C. Igei, S. Kobata, J. Koyama, R. Tomori, N. Kawamitsu, Y. Yamamoto, M. Tsuchida, Y Tokeshi, R. Ikemura, K. Miyagi, K. Okiyama, and K. Iha, "Use of a modified early warning score system to reduce the rate of in-hospital cardiac arrest," J. Intensive Care, vol. 4, no. 2, 2016.

[16] Departemen Kesehatan Republik Indonesia, "Riset Kesehatan Dasar laporan tahun 2007," Jakarta, 2008.

[17] Riskesdas, "Riset Kesehatan Dasar," Jakarta, 2013.

[18] 